\title{
ASUHAN KEBIDANAN KOMPREHENSIF BBL PADA BY"I" DENGAN BBLR HARI KE-2 DI RSI NASHRUL UMMAH LAMONGAN TAHUN 2015
}

\author{
Ida Susila* \\ Dini Novia Sari**
}

*Dosen Program Studi Diploma III Kebidanan Universitas Islam Lamongan
**Mahasiswa Program Studi Diploma III Kebidanan Universitas Ialam Lamongan

\section{RINGKASAN}

Berat Bayi Lahir Rendah (BBLR) merupakan bayi baru lahir yang berat badannya saat lahir kurang dari 2500 gram. Di RSI Nashrul Ummah Lamongan masih terdapat bayi baru lahir dengan BBLR sebesar $(8,98 \%)$.

Metode yang dipakai dalam penyusunan laporan tugas akhir ini deskriptif observasi yang dilaksanakan dengan pendekatan kohort mulai dari kehamilan sampai kontrasepsi diperoleh melalui wawancara, pengkajian data primer, skunder, pemeriksaan fisik, penunjang dan dilakukan pendokumentasian standar kebidanan SOAP.

Asuhan kebidanan pada bayi baru lahir dengan berat bayi lahir rendah terdapat kesenjangan pada data obyektif untuk pemeriksaan neurologi.

Berdasarkan hasil dari asuhan kebidanan pada bayi baru lahir dengan berat bayi lahir rendah, dilakukan pemeriksaan reflek-reflek neurologi dengan hasil pada reflek menelan, menghisap dan reflek mengangkat leher masih lemah. Sedangkan pada teori mengatakan bahwa semua reflek neurologi lemah pada bayi dengan berat lahir rendah.

Kata Kunci : BBL, BBLR, Hari ke-2

\section{PENDAHULUAN}

\section{Latar Belakang}

Keadaan bayi sangat tergantung pada pertumbuhan janin dalam uterus, kualitas pengawasan antenatal, penanganan persalinan dan perawatan setelah lahir. Kejadian bayi dengan berat badan yang rendah masih sangat tinggi di negara berkembang ini merupakan akibat rendahnya status sosial ekonomi dan tingkat pendidikan yang dimiliki kebanyakan masyarakat sehingga kesadaran dan pemahaman mengenal kondisi kehamilannya masih sangat kurang akibatnya dapat terjadi komplikasi pada bayi seperti asfiksia dan mengakibatkan meningkatnya mordibitas dan mortalitas terhadap bayi.

Dari data RSI Nashrul Ummah Lamongan pada tahun 2014 jumlah bayi yang lahir 515 bayi, jumlah bayi yang lahir normal sebanyak bayi $471(91,4 \%)$ dan yang mengalami BBLR sebanyak 21 bayi $(4,1 \%)$. Sedangkan dari data RSI Nashrul Ummah Lamongan pada bulan Januari - Juni tahun 2015 jumlah bayi yang lahir 178 bayi, dengan angka kejadian bayi dengan BBLR sebanyak 16 bayi (8.98\%). Faktor penyebab Berat Bayi

Lahir Rendah (BBLR) adalah terjadinya interaksi antara sosiodemografi, status gizi ibu hamil, status obstetrik, sosial ekonomi 
keluarga, dan faktor instriksi janin. Jadi secara garis besar Berat Bayi Lahir Rendah (BBLR) dipengaruhi oleh dua faktor yaitu faktor maternal dan faktor janin. Faktor maternal yang mempengaruhi kejadian Berat Bayi Lahir Rendah (BBLR) adalah usia ibu, paritas, sosial ekonomi yang rendah, penyakit akut atau kronik ibu hamil, perdarahan antepartum, cervik yang tidak kompeten, kelainan bentuk uterus, kelainan plasenta, jarak kehamilan, aktivitas fisik ibu, kebiasaan buruk ibu (merokok dan konsumsi narkoba), status gizi ibu hamil yang kurang, pendidikan ibu yang rendah, akses terhadap tenaga kesehatan kurang. Sedangkan faktor janin yang berperan pada kejadian Berat Bayi Lahir Rendah (BBLR) jenis kelamin, etnik atau ras dan kelainan kongenital.

Sebagai tenaga kesehatan khususnya bidan, tindakan yang dapat dilakukan adalah dengan melakukan upaya pencegahan (preventif) yakni dengan mendeteksi dini komplikasi hingga menangani komplikasi sesuai dengan standar yang telah ditetapkan dan mengupayakan agar setiap kehamilan dapat diperiksa oleh bidan, sehingga komplikasi dapat terdeteksi lebih dini dan dapat ditangani sesegera mugkin. Serta adanya dukungan dari suami atau keluarga pasien diharapkan dapat memberikan rasa tenang dan aman pada ibu hamil selama proses kehamilan. Sehingga dari keadaan tersebut dapat menimbulkan rasa kerja sama dan tanggung jawab yang baik diantara bidan dan keluarga pasien. Sehingga angka Berat Bayi Lahir Rendah (BBLR) dapat dikurangi.

\section{Tujuan Penelitian}

Mahasiswa mampu

menerapkan dan malaksanakan Asuhan Kebidanan dengan manajemen (SOAP) di antaranya adalah melakukan pengkajian data subyektif pada kasus Berat Bayi Lahir Rendah (BBLR), melakukan pengkajian data obyektif pada kasus Berat Bayi Lahir Rendah (BBLR), melakukan analisa data obyektif dan subyektif pada kasus Berat Bayi Lahir Rendah (BBLR), melakukan penatalaksanaan asuhan kebidanan pada kasus Berat Bayi Lahir Rendah (BBLR).

\section{PEMBAHASAN}

Pembahasan merupakan bagian dari Laporan Tugas Akhir yang berisi uraian secara mendalam tentang perbedaan/kesenjangan dan persamaan antara tinjauan pustaka dengan tinjauan kasus yang terjadi selama penulis melaksanakan asuhan kebidanan komprehensif BBL By"I" hari ke-2 dengan BBLR di RSI Nashrul Ummah Lamongan.

\section{Data Subyektif}

Pada data subyektif terdapat persamaan antara tinjauan kasus dan tinjauan teori yang terletak pada keluhan utama. Pada teori dijelaskan bahwa keluhan utama pada bayi dengan berat bayi lahir rendah yaitu bayi kecil, berat badan kurang, bayi menangis, merintih, lemas, dan gerakan kurang aktif. Sedangkan pada kasus bayi mengalami berat lahir yang kurang, bayi terlihat kecil, bayi menangis merintih, lemas dan gerakan kurang aktif.

Dikuatkan dengan teori yang menyebutkan bahwa Berat Bayi Lahir Rendah (BBLR) ialah bayi baru lahir yang berat badannya saat lahir kurang dari 2500 gram (sampai 
dengan 2499 gram) (Sarwono : 2010).

Bayi baru lahir dengan berat bayi lahir rendah selalu mengalami tanda-tanda seperti suara tangisan merintih, gerakan yang lemah, dan keadaan umum yang lemah. Opini ini dikuatkan oleh teori yang menyebutkan bahwa tanda-tanda bayi dengan berat lahir rendah yaitu tonus otot lemah sehingga bayi kurang aktif dan pergerakanya lemah, fungsi saraf yang belum atau tidak efektif dan tangisnya lemah, jaringan kelenjar mammae masih kurang akibat pertumbuhan otot dan jaringan lemak masih kurang, dan verniks kaseosa tidak ada atau sedikit bila ada (Sarwono, 2010).

\section{Data Obyektif}

Terdapat kesenjangan pada data obyektif untuk pemeriksaan neurologi, diteori dijelaskan bahwa hasil dari pemeriksaan neurologi semua reflek-refleknya lemah, sedangkan pada kasus hanya reflek menghisap, menelan dan tonic neck saja yang lemah.

Kesenjangan ini dikuatkan oleh teori yang menyebutkan bahwa reflek-reflek neurologi yang terjadi pada bayi dengan berat lahir rendah mengalami reflek yang lemah dikarenakan organ-organ tubuh bayi masih belum berfungsi secara sempurna.

Reflek - reflek pada

pemeriksaan neurologi dengan kasus berat bayi lahir rendah tidak semuanya lemah, karena lemah atau tidaknya reflek tergantung dari keadaan umum dan kesadaran dari bayi tersebut.

Dikuatkan dengan teori yang menyebutkan bahwa ciri-ciri dari bayi dengan berat bayi lahir rendah berat badan kurang dari 2500 gram, rambut tipis halus, tulang tengkorak lunak, tulang rawan dan daun telinga imatur, kulit tipis dan transparan, terdapat rambut lanugo terutama pada dahi, pelipis, telinga, lengan, serta reflek-reflek pada pemeriksaan neurologis lemah, terutama pada reflek menghisap, menelan, dan reflek tonus leher lemah.

\section{Analisa}

Tidak terdapat kesenjangan pada analisa data antara tinjauan kasus dan tinjauan teori, pada tinjauan kasus dan tinjauan teori menyebutkan bahwa pada masalah potensial bayi dengan berat bayi lahir rendah mengalami hipoglikemi, hipotermi, dan asfiksi neonatorum.

Diperkuat oleh teori yang menyebutkan bahwa komplikasi yang terjadi pada Berat Bayi Lahir Rendah merupakan hipoglikemi, hipotermi, asfiksi neonatorum, hiperbilirubinemia, pneumoni aspirasi, dan infeksi. (Wahidayat : 2007).

Bayi baru lahir dengan berat bayi lahir rendah (BBLR) lebih sering mengalami beberapa komplikasi seperti hipotermi, asfiksi, hipoglikemi, hiperbilirubinemia, pneumoni aspirasi serta infeksi. Biasanya bayi dengan berat lahir yang semakin rendah akan semakin mudah mengalami komplikasi tersebut.

Opini ini dikuatkan oleh teori yang menyebutkan bahwa bayi dengan berat lahir rendah akan lebih rentan mengalami komplikasi seperti asfiksia neonatorum, hipotermi, hipoglikemi, hiperbilirubinemia, pneumoni aspirasi, dan infeksi, dikarenakan pertumbuhan janin dalam rahim yang terhambat sehingga fungsi organ-organ dalam tubuh janin belum berfungsi semua. 


\section{Penatalaksanaan}

Pada kasus bayi dengan berat bayi lahir rendah didapatkan adanya kesenjangan pada penatalaksanaan antara kasus dan teori. Pada teori menyebutkan bahwa penatalaksanaan yang dilakukan pada bayi dengan berat lahir rendah yaitu menghangatkan bayi, pemenuhan nutrisi , mengkaji reflek-reflek neurologi, melakukan penimbangan secara ketat, dan perawatan bayi baru lahir sehari-hari. Sedangkan pada kasus menyebutkan bahwa bayi masih dipuasakan karena lambung bayi masih belum bisa menerima asupan nutrisi dan setelah dilakukan retensi lambung ternyata konsistensi dari retensi hitam dan banyak.

Kesenjangan ini diperkuat oleh teori yang menyebutkan bahwa bayi dengan berat lahir rendah seharusnya segera diberikan nutrisi untuk memenuhi kebutuhan nutrisi tubuhnya. Tetapi jika pada saat diberikan ASI dan bayi memuntahkan atau mengeluarkannya kembali maka lebih baik pemberian ASI dihentikan/bayi dipuasakan untuk sementara waktu sampai lambung bayi bisa menerima asupan nutrisi. Jika lambung bayi sudah bisa menerima nutrisi maka segera berikan ASI sesuai kebutuhan bayi.

Pada bayi dengan berat bayi lahir rendah sebaiknya segera dilakukan pemenuhan nutrisi berupa ASI. Karena ASI akan dapat membantu proses menaikkan berat badan bayi, serta dapat membentuk kekebalan tubuh bayi sejak kecil.

Opini ini diperkuat dengan teori yang menyebutkan bahwa ASI merupakan cairan tubuh yang dinamis, dan komposisi ASI senantiasa berubah untuk memenuhi kebutuhan nutrisi bayi. ASI pertama yang dikonsumsi bayi, yang disebut fore-milk (ASI awal), mengandung kadar lemak yang lebih rendah, yang secara konstan meningkat kadarnya dalam hind-milk (ASI akhir), dan ini yang diduga mendasari timbulnya rasa puas atau kenyang pada bayi.

\section{Kesimpulan}

Pada pengkajian data subyektif terdapat persamaan antara tinjauan teori dan tinjauan kasus pada keluhan utama yaitu bayi kecil, berat badan kurang, bayi menangis merintih, lemas dan gerakan kurang aktif. Pada pengkajian data obyektif terdapat kesenjangan antara tinjauan teori dan tinjauan kasus pada pemeriksaan reflek neurologi. Pada analisa data tidak terdapat kesenjangan antara tinjauan teori dan tinjauan kasus yakni pada masalah potensiall bayi mengalami hipotermi, asfiksi, dan hipoglikemi.

Penatalaksanaan terdapat kesenjangan antara tinjauan teori dan tinjauan pada pemenuhan kebutuhan nutrisi.

\section{Saran}

Diharapkan dapat meningkatkan kualitas pelayanan bagi petugas dan klien sehingga tercapai asuhan kebidanan yang lebih komprehensif. Diharapkan dapat meningkatkan pemahaman tentang informasi yang berhubungan dengan Berat Bayi Lahir Rendah (BBLR) akan membantu masyarakat dalam mendeteksi dini komplikasi dan tindakan yang harus dilakukan agar tidak terjadi hal yang tidak diinginkan.

\section{DAFTAR PUSTAKA}

Bagian Ilmu Kesehatan Anak, FKUI. 2007. Buku Kuliah 3 Ilmu 
Kesehatan Anak. Jakarta: Infomedika

Hidayat, A. Aziz Aminul. 2008. Pengantar Ilmu Keperawatan Anak 1. Jakarta : Salemba medika

Mansjoer, Arif, dkk. 2008. Kapita Selekta Kedokteran Edisi Ketiga Jilid 1. Jakarta : Media Aesculapius

Manuaba, IBG. 2010. Ilmu Kebidanan, Penyakit Kandungan dan Keluarga Berencana untuk Pendidikan Bidan. Jakarta : EGC

Muslihatun, Wafi Nur. 2010. Asuhan Neonatus Bayi dan Balita. Yogyakarta : Fitramaya

Prawirohardjo, Sarwono. 2008. Ilmu Kebidanan. Jakarta : YBP-SP

Prawirohardjo, Sarwono. 2010. Pelayanan Kesehatan Maternal dan Neonatal. Jakarta : YBP SP

Rukiyah, Ai Yeyeh. 2010. Asuhan Kebidanan IV (Patologi Kebidanan). Jakarta : Trans Info Media

Saifuddin, Abdul Bahri. 2010. Buku Panduan Praktis Pelayanan Maternal Neonatal. Jakarta : Yayasan Bina Pustaka Sarwono Prawirohardjo

Soetjiningsih. 2008. Tumbuh Kembang Anak. Jakarta : EGC Wahidayat, Prof. DR. Iskandar. 2007. Ilmu Kesehatan Anak. Jakarta :

FKUI 